\title{
Клеточная иммунология
}

(C) Коллектив авторов, 2020

Борисевич Г.В., Кириллова С.Л., Петров А.А., Лебедев В.Н., Пащенко Ю.И., Кириллов В.Б., Сизикова Т.Е., Павельев Д.И., Пантюхов В.Б., Кутаев Д.А., Борисевич С.В.

\section{Анализ основных и малых популяций лимфоцитов периферической крови макак резус с использованием метода проточной цитометрии}

Федеральное государственное бюджетное учреждение «48 Центральный научно-исследовательский институт» Министерства обороны Российской Федерации, 141306, г. Сергиев Посад-6, Московская область, Российская Федерация

\section{Резюме}

Введение. При оценке иммунного статуса человека и животных наряду с основными популяциями лимфоцитов в ряде случаев необходимо учитывать данные о малых субпопуляциях лимфоцитов и пулах активированных клеток.

Цель работы - определение наличия и интервалов распределения основных и малых популяций лимфоцитов в периферической крови здоровых макак резус с использованием многоцветного цитометрического анализа и сравнение полученных результатов с соответствующими показателями людей.

Материал и методы. Использовали венозную кровь 17 здоровых неполовозрелых самцов макак резус возрастом 2,0-2,5 года. Цельную кровь животных окрашивали конъюгированными с флуорохромами мышиными античеловеческими моноклональными антителами, перекрестно реагирующими с антигенами лимфоцитов макак резус. Определение популяций лимфоцитов обезьян проводили с использованием метода проточной цитометрии. Полученные результаты сравнивали с аналогичными данными детей и подростков, опубликованными в отечественных научных изданиях.

Результаты. Определены 20 основных и малых популяций лимфоцитов макак резус, изучен спонтанный уровень экспрессии в субпопуляциях Т-клеток маркеров ранней (CD25) и поздней (HLA-DR) активации лимфоцитов. У макак резус наблюдается достоверно более низкое относительное содержание Т-лимфоцитов, НКТ-клеток, Т-хелперов, цитотоксических Т-лимфоцитов, двойных негативных Т-лимфоцитов, Т-лимфоцитов, экспрессирующих маркер ранней активации, Т-хелперов, экспрессирующих маркер ранней активации, Т-регуляторных клеток, но более высокое - В-лимфоцитов, натуральных киллеров, CD8-позитивных натуральных киллеров, двойных позитивных Т-лимфоцитов, Т-лимфоцитов, экспрессирующих маркер поздней активации, Т-хелперов, экспрессирующих маркер поздней активации, и цитотоксических Т-лимфоцитов, экспрессирующих маркер поздней активации $(p<0,05)$.

Заключение. Определение методом проточной цитометрии показателей основных, малых и активированных популяций лимфоцитов макак резус позволит при моделировании заболеваний человека на животных оценить не только период начала иммунного ответа и его характер, но и даст возможность спрогнозировать течение заболевания, осуществить лабораторный мониторинг терапии, а в будущем использовать лимфоциты в качестве мишеней терапевтического воздействия.

Ключевые слова: лимфоциты; макаки резус; проточная цитометрия; маркеры ранней и поздней активации

Статья получена 05.07.2020. Принята в печать 15.08.2020.

Для цитирования: Борисевич Г.В., Кириллова С.Л., Петров А.А., Лебедев В.Н., Пащенко Ю.И., Кириллов В.Б., Сизикова Т.Е., Павельев Д.И., Пантюхов В.Б., Кутаев Д.А., Борисевич С.В. Анализ основных и малых популяций лимфоцитов периферической крови макак резус с использованием метода проточной цитометрии. Иммунология. 2020; 41 (5): 411-420. DOI: https://doi.org/10.33029/0206-4952-2020-41-5-411-420

Финансирование. Исследование не имело спонсорской поддержки.

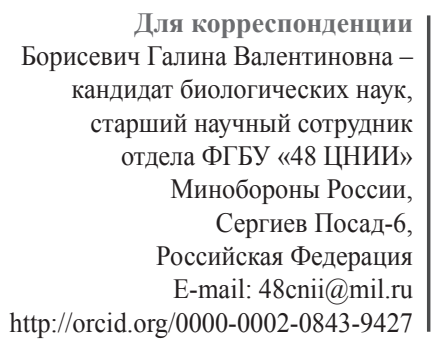

Для корреспонденции Борисевич Галина Валентиновна кандидат биологических наук, старший научный сотрудник отдела ФГБУ «48 ЦНИИ» Минобороны России, Сергиев Посад-6,

Российская Федерация E-mail: 48cnii@mil.ru http://orcid.org/0000-0002-0843-9427

Конфликт интересов. Авторы заявляют об отсутствии конфликта интересов. 
Borisevich G.V., Kirillova S.L., Petrov A.A., Lebedev V.N., Pashchenko Yu.I., Kirillov V.B., Sizikova T.E., Paveliev D.I., Pantyukhov V.B., Kutaev D.A., Borisevich S.V.

\section{Analysis of main and small populations of lymphocytes of rhesus macaque peripheral blood using the method of flow cytometry}

48 Central Scientific Research Institute of the Ministry of Defense of the Russian Federation, 141306, Sergiev Posad-6, Russian Federation

\section{Abstract}

Introduction. When assessing the immune status of humans and animals, along with the main populations of lymphocytes, in some cases, it is necessary to take into account data on small subpopulations of lymphocytes and pools of activated cells.

The aim - determination presence and intervals of main and small lymphocytes populations distribution in the peripheral blood of healthy rhesus macaque using multicolored cytometric analysis and comparison of the date obtained with the corresponding characteristics of humans.

Material and methods. Venous blood of 17 healthy Macaca mulatta males 2.0-2.5 years old was used in the experiments. Whole blood of animals was stained with fluorochromeconjugated mouse anti-human monoclonal antibodies that cross-react with rhesus monkey lymphocyte antigens. Determination of the populations of monkey lymphocytes was carried out using the flow cytometry method. The results obtained were compared with similar data for children and adolescents published in Russian scientific journals.

Results. We identified 20 major and small populations of rhesus monkey lymphocytes, studied the spontaneous expression level of markers of early (CD25) and late (HLA-DR) lymphocyte activation on T-cell subpopulations. In rhesus monkeys, a significantly lower relative content of T-lymphocytes is observed; NKT cells, T-helpers, cytotoxic T-lymphocytes, double negative T-lymphocytes, T-lymphocytes expressing an early activation marker, T-helpers expressing an early activation marker, T-regulatory cells, but higher - B-lymphocytes, natural killer cells, CD8 positive natural killer cells, double-positive T-lymphocytes, T-lymphocytes expressing a late activation marker, T-helpers expressing a marker of late activation, and cytotoxic T-lymphocytes expressing a marker of late activation $(p<0.05)$.

Conclusion. Determination by flow cytometry of indicators of the main, small and activated lymphocytes of rhesus monkeys will allow, when simulating human diseases in animals, to assess not only the period of the onset of the immune response and its nature, but also make it possible to predict the course of the disease, carry out laboratory monitoring of therapy, and in the future will allow the use of lymphocytes as targets of therapeutic action.

Keywords: lymphocytes; rhesus macaques; flow cytometry; markers of early and late activation

Received 05.07.2020. Accepted 15.08.2020.

For citation: Borisevich G.V., Kirillova S.L., Petrov A.A., Lebedev V.N., Pashchenko Yu.I., Kirillov V.B., Sizikova T.E., Paveliev D.I., Pantyukhov V.B., Kutaev D.A., Borisevich S.V. Analysis of main and small populations of lymphocytes of rhesus macaque peripheral blood using the method of flow cytometry. Immunologiya. $2020 ; 41$ (5): 411-20. DOI: https://doi.org/10.33029/0206-4952-2020-41-5-411-420 (in Russian)

Funding. The study had no sponsor support.

Conflict of interests. The authors declare no conflict of interests.

\section{Введение}

Нечеловекообразные приматы (НЧП) используются во многих областях биологии и медицины: в фармакологии, где они могут быть единственной релевантной моделью in vivo при оценке безопасности некоторых типов биотехнологических кандидатов, при исследовании патофизиологии инфекционных заболеваний (например, СПИДа), при изучении строения и функций мозга, при разработке и тестировании методов ксенотрансплантации и др. $[1,2]$. Результаты изучения иммунного статуса, полученные после экспериментального воздействия на обезьян рода макак, включающего вид макака резус (Macaca mulatta), можно экстраполировать на человека, поскольку у обезьян данного вида организация кроветворной и иммунной систем, структура биологически значимых молекул почти идентична 
Таблица 1. Перечень панелей моноклональных антител, использованных для фенотипирования лимфоцитов макак резус

\begin{tabular}{|c|c|c|c|c|c|}
\hline \multirow[t]{2}{*}{ Изучаемые популяции и субпопуляции лимфоцитов } & \multicolumn{5}{|c|}{$\begin{array}{c}\text { Распределение флуорохромов и меченных } \\
\text { ими моноклональных антител по кана- } \\
\text { лам флуоресценции }\end{array}$} \\
\hline & FITC & PE & ECD & PC5 & PC7 \\
\hline $\begin{array}{l}\text { Т-общие, В-общие, натуральные киллеры (НК), Т-лимфоциты, экспрес- } \\
\text { сирующие маркеры НК-клеток (НКТ-клетки) }\end{array}$ & CD16 & CD19 & $*$ & * & CD3 \\
\hline $\begin{array}{l}\text { T-хелперы, цитотоксические Т-лимфоциты, двойные позитивные Т-лим- } \\
\text { фоциты, двойные негативные Т-лимфоциты, активированные субпопу- } \\
\text { ляции Т-лимфоцитов, НК, экспрессирующие CD8 }\end{array}$ & CD25 & CD4 & HLA-DR & CD8 & CD3 \\
\hline Т-регуляторные клетки (Трег) & $\mathrm{CD} 25$ & CD4 & * & CD127 & CD3 \\
\hline
\end{tabular}

Примечание. *-канал флуоресценции не используется.

человеческой [3]. Следует отметить, что моноклональные антитела (МкАт) против антигенов человека часто распознают гомологичные детерминанты лейкоцитов обезьян указанного вида [4].

Клетки иммунной системы отвечают на внедрение патогена изменением субпопуляционного состава и экспрессии мембранных и внутриклеточных маркеров, появлением на клеточной поверхности определенных функциональных молекул [5]. Изучение патогенеза различных заболеваний выявило ключевую роль в их развитии регуляторных Т-клеток, субпопуляций Ви НК-клеток, активированных лимфоцитов. При оценке иммунного статуса человека и животных, наряду с основными популяциями лимфоцитов, в ряде случаев необходимо учитывать данные о малых субпопуляциях лимфоцитов и пулах активированных клеток [6]. Поэтому целью данного исследования было определение наличия и интервалов распределения основных и малых популяций лимфоцитов в периферической крови здоровых макак резус с использованием многоцветного цитометрического анализа и сравнение полученных данных с соответствующими показателями у человека.

\section{Материал и методы}

В экспериментах использовали 17 здоровых самцов макак резус в возрасте 2,0-2,5 года, массой 2,5-3,0 кг, которых содержали в питомнике ФГБУ «48 ЦНИИ» Минобороны России. Уход за животными осуществляли в соответствии с ГОСТом 33218-2014 (Правила содержания и ухода за нечеловекообразными приматами) и Федеральным законом РФ «Об ответственном обращении с животными» (№ 498-Ф3 от 27.12.2018). Средние значения показателей лимфоцитов периферической крови для каждого из 17 животных рассчитывали в 3-4 повторностях.

Венозную кровь приматов, полученную утром натощак пункцией периферической вены, собирали в вакуумные пробирки с напылением К ЭДТА. С момента взятия крови до начала исследований проходило от 0,5 до 1,0 ч. Методология иммунофенотипирования лимфоцитов обезьян существенно не отличается от той, что используется для человека [7], поэтому составление цитометрических панелей, распределение антител по каналам флуоресценции, настройку протоколов анализа проводили в соответствии со стандартизованной технологией [8] и принципами формирования панелей для многоцветных цитофлуориметрических исследований [9]. Панели МкАт, использованные для фенотипирования лимфоцитов макак резус, представлены в табл. 1.

В работе использовали перекрестно реагирующие с антигенами лимфоцитов макак резус клоны мышиных античеловеческих МкАт различных производителей: Affymetrix eBioscience (США) (CD25-FITC, клон CD25-4E3, кат. № 11-0257; CD4-PE, клон OKT4, кат. № 12-0048; CD127-PE-Сy5, клон eBioRDR5, кат. № 151278); Beckman Coulter (США) (CD8-PC5, клон В9.11, кат. № A07758; HLA-DR-ECD, клон Immu357, кат. № IM3636); Becton Dickinson (CШA) (CD3-PE-Cy7, клон Sp34-2, кат. № 557749); Novus (США) (CD19-PE, клон NBP2-26646, кат. № 6602868); Serotec (США) (CD16-FITC, клон 3G8, кат. № MCA1569F). Перекрестная реактивность антител с антигенами макак резус подтверждена производителями антител. Для идентификации натуральных киллеров макак резус не использовали маркер CD56, так как в выполненных ранее исследованиях показана малочисленность по-

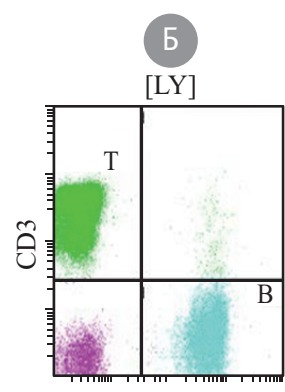

CD19

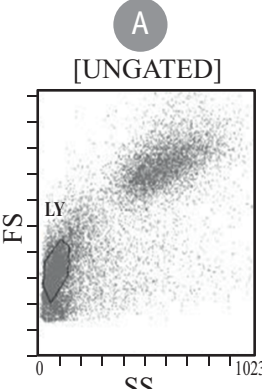

SS

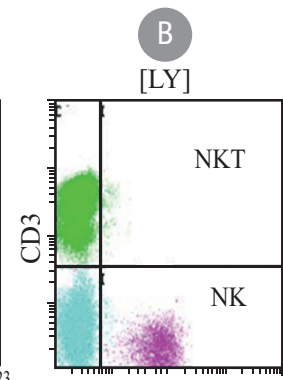

CD16
Рис. 1. Распределение маркеров CD3, CD16 и CD19 на лимфоцитах макак резус

Гистограмма А не гейтирована (ungated): выделение популяиии лимфочитов (LY) по параметрам бокового (SS) и прямого (FS) светорассеяния. Гистограммы Б (CD19 против CD3) и B (CD16 против CD3) гейтированы по области [LY] гистограммы A, предназначены для выявления относительного содержания от лимфоцитов: Т-лимфоцитов (T), В-лимфоцитов (B), натуральных киллеров (НК) и НКТ-клеток (НКТ). 


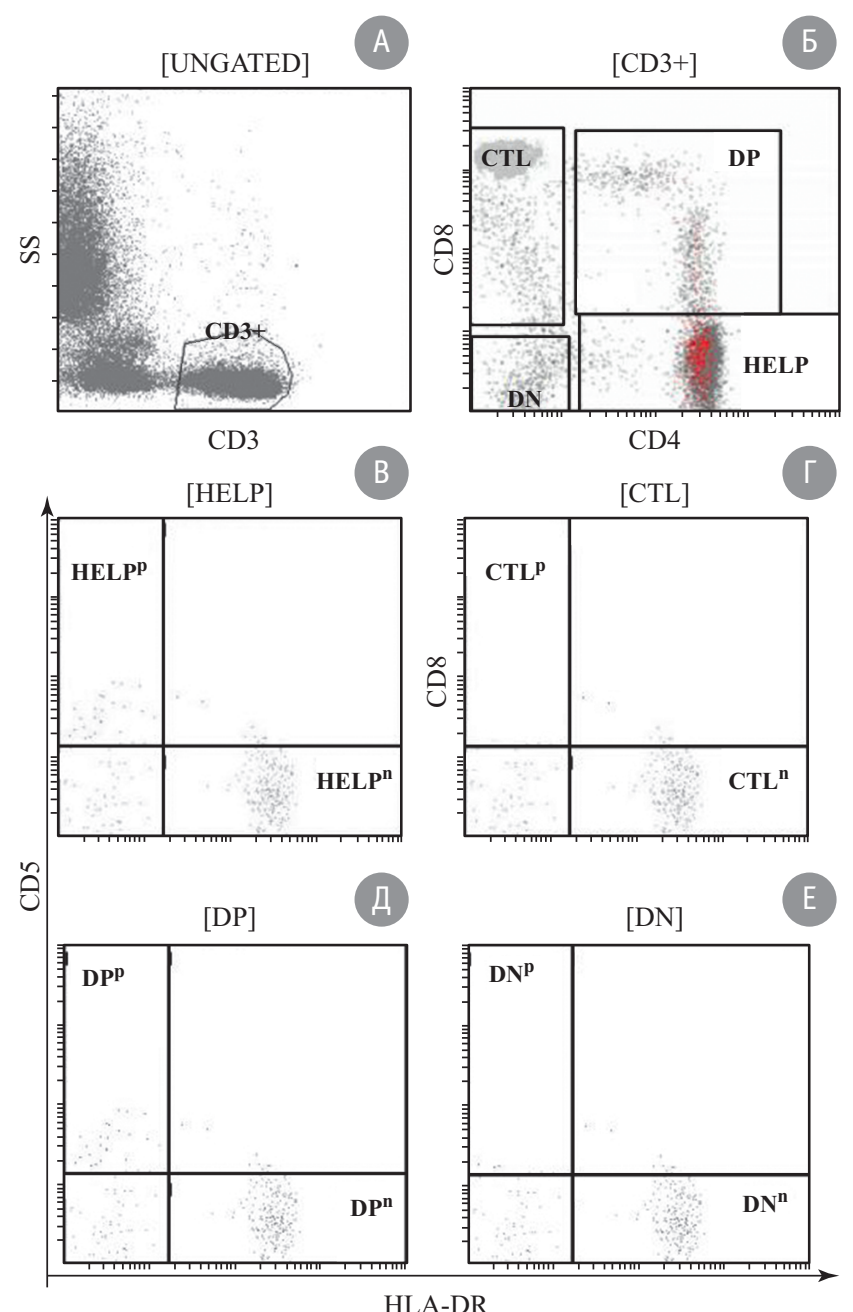

Рис. 2. Распределение маркеров CD25 и HLA-DR на T-лимфоцитах макак резус

Гистограмма А не гейтирована: выделение Т-лимфоцитов (область $\mathrm{CD}^{+}$) по уровню экспрессии $C D 3$ и бокового светорассеяния (SS). Гистограмма Б гейтирована по области $\left[\mathrm{CD}^{+}\right]$гистограммы A, CD4 против CD8, предназначена для выявления относительного содержания от Т-лимфоцитов T-хелперов (HELP), цитотоксических Т-лимфочитов (CTL), двойных позитивных $T$-лимфоцитов (DP) и двойных негативных T-лимфочитов (DN). Гистограммы B-E предназначень для выявления относительного содержания клеток, несущих маркеры ранней $\left(C D 25^{+}\right)$и поздней активации $\left(H L A-D R^{+}\right)$, от соответствующих популячий T-лимфочитов. $H E L P$, $C T L^{p}$, $D P^{p}$ и $D N^{p}$ - несущие маркер ранней активащии субпопулящии T-лимфочитов. $H E L P^{n}, C T L^{n}, D P^{n}$ и $D N^{n}-$ несущие маркер поздней активации субпопуляции Т-лимфоцитов.

пуляции CD56 + -HК-клеток или даже отсутствие экспрессии данной молекулы на лимфоцитах этого вида приматов $[10,11]$.

Для выделения представляющих интерес популяций лимфоцитов были использованы логические ограничения (тактики гейтирования), представленные на рис.1-3.

Для устранения неспецифического связывания и оптимизации использования антител определяли их рабочие объемы путем титрования, рассчитывая для каждого разведения индекс окрашивания (Stain Index) [12]. При настраивании протоколов анализа для установления границ между отрицательными и положительными событиями при использовании антител против маркеров CD25, CD127 и HLA-DR применяли соответствующие изотипические контроли производства Affymetrix eBioscience (США) (IgG2b-FITC, кат. № 114732; IgG1-PE-Cy5, кат. № 15-4714) и Beckman Coulter (CША) (IgG1-ECD, кат. № A07797). Для проверки корректности настройки компенсации применяли FMOподход (Fluorescence-Minus-One, флуоресценция минус один).

Цельную кровь помещали в пробирки с предварительно внесенными МкАт и перемешивали в течение 1 с на встряхивателе Vortex, далее инкубировали 15 мин в темном месте при комнатной температуре. Для лизиса эритроцитов использовали реагенты OptiLyse C и VersaLyse (Beckman Coulter, США, кат. № 11895 и А09777) в соответствии с рекомендациями производителя. Далее образцы дважды отмывали в фосфатносолевом буфере, центрифугируя по 5 мин при $400 \mathrm{~g}$. Для анализа клетки ресуспендировали в фиксирующем буфере, содержащем $0,1 \%$ формальдегида. Иммунофенотипирование проводили на цитофлуориметре FC500 Cytomics (Beckman Coulter, CША), оснащенном аргоновым лазером с длиной волны излучения 488 нм с программным обеспечением СХР, версия 2.3. В каждой пробе исследовали не менее 10000 лимфоцитов.

Показатели анализировали средствами MS Excel с использованием общеизвестных статистических методов и критериев. За уровень статистической значимости была принята величина, равная 0,05 .

\section{Результаты}

С использованием 3 панелей МкАт были определены значения показателей 20 популяций лимфоцитов периферической крови макак резус. Для группы из 17 животных рассчитывали следующие статистические характеристики показателей лимфоцитов периферической крови: минимальную и максимальную среднюю величины $\left(\mathrm{X}_{\text {мин }}\right.$ и $\mathrm{X}_{\text {макс }}$ соответственно), среднюю величину и ее доверительный интервал $X_{\text {ср }}\left(I_{95}\right)$, центральный (медиану), нижний и верхний квартили $\left(\mathrm{Me}, \mathrm{Q}_{25}\right.$ и $\mathrm{Q}_{75}$ coответственно), коэффициент вариации (V). Указанные статистические характеристики представлены в табл. 2 . Для всех популяций лимфоцитов результаты расчетов отражают близость значений $\mathrm{X}_{\mathrm{cp}}$ и $\mathrm{Me}$, поскольку $\mathrm{X}_{\mathrm{cp}}$ находится в диапазоне $\left(\mathrm{Q}_{25}-\mathrm{Q}_{75}\right)$. Такая особенность характерна для симметричных распределений (в том числе для нормального распределения), что позволяет использовать методы параметрической статистики [13].

Клинические проявления и лабораторные показатели при моделировании патологических состояний на обезьянах могут зависеть не только от их вида, но и от возраста, поэтому сравнение иммунологических показателей обезьян и человека следует проводить в соответствующих возрастных группах [14]. Учитывая 
сроки наступления половой зрелости (у самцов макак резус она наступает в 4 года) и возрастные физиологические особенности вида M. mulatta, изучаемые особи относятся к группе неполовозрелых [15]. Поскольку в экспериментах использовали животных, не достигших половой зрелости, то наиболее корректно сравнение полученных показателей макак резус и условно здоровых детей.

Результаты иммунофенотипирования лимфоцитов макак резус сравнивали с аналогичными данными детей и подростков, опубликованными в отечественных научных изданиях, и представленными в табл. 2 [16, 17]. Для детей и подростков относительное и абсолютное количество основных субпопуляций лимфоцитов периферической крови не имеют устойчивой зависимости от пола и возраста, поэтому для данных возрастных рамок приводятся единые значения [18]. Показатели клеточной составляющей иммунного статуса неполовозрелых макак резус до 3-летнего возраста подчиняются таким же закономерностям [19]. Следует отметить большую вариабельность показателей лимфоцитов периферической крови макак резус, так же, как и условно здоровых детей.

В отношении условно здоровых детей мы располагали только данными о средних значениях и/или медианах для 16 из 20 исследованных нами показателей, а также их доверительных границах (для уровня вероятности $p<0,05)$. Поэтому проверку нулевой гипотезы (равенства средних значений показателей макак резус и детей) проводили путем сопоставления границ доверительных интервалов средних значений показателей [13], за исключением CD8+-НК-клеток, где сравнивали нижний, центральный (медиану) и верхний квартили показателя.

Следует отметить, что для большинства показателей установлены достоверные различия между сравниваемыми группами. У макак резус наблюдается достоверно более низкое относительное содержание Т-лимфоцитов, НКТ-клеток, Т-хелперов, цитотоксических Т-лимфоцитов, двойных негативных Т-лимфоцитов, Т-лимфоцитов, экспрессирующих маркер ранней активации, Т-хелперов, экспрессирующих маркер ранней активации, Трег, но более высокое - В-лимфоцитов, $\mathrm{CD}^{+}$-НК-клеток, двойных позитивных Т-лимфоцитов, Т-лимфоцитов, экспрессирующих маркер поздней активации, Т-хелперов, экспрессирующих маркер поздней активации, и цитотоксических Т-лимфоцитов, экспрессирующих маркер поздней активации $(p<0,05)$.

Для показателя НК-клеток наблюдается пересечение доверительных интервалов его средних значений у обезьян и детей. Однако расчет критерия различий между средними значениями 2 выборок с учетом их разного объема [13] показал существенное превышение фактического значения величины нормированного отклонения $t_{\phi}$ по сравнению с его стандартной величиной $t_{s t}$ что позволяет отвергнуть нулевую гипотезу о равенстве

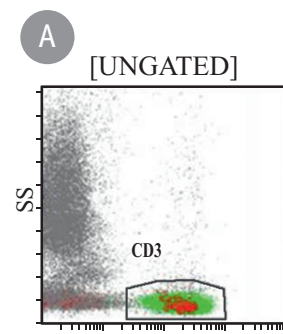

CD3

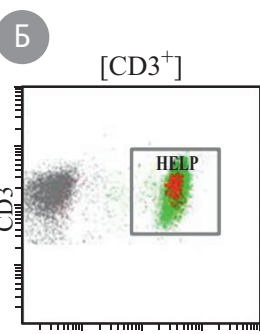

CD4

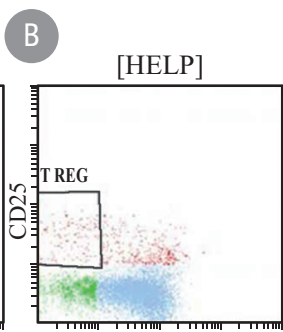

CD127
Рис. 3. Определение Т-регуляторных клеток макак резус Гистограмма А (см. обозначение рис. 2). Гистограмма Б гейтирована по области $\left[\mathrm{CD}^{+}\right]$гистограммы A, CD4 против CD3, предназначена для выявления относительного содержания T-хелперов от T-лимфоциитов, область [HELP]. Гистограмма B гейтирована по области [HELP] гистограммы Б, СD127 против CD25, предназначена для выявления относительного содержсания T-регуляторных клеток от T-хелперов, область [TREG].

средних значений. Таким образом, с вероятностью $95 \%$ средние значения показателя НК-клеток у обезьян и детей достоверно различаются.

\section{Обсуждение}

Сведения о функционировании иммунной системы НЧП, в частности макак резус, имеют существенную практическую значимость, поскольку данный вид животных является благоприятной моделью для доклинического изучения механизмов заболеваний человека, потенциала терапевтических и иммунобиологических препаратов. Развитие проточной цитометрии привело к широкому применению оценки основных популяций лимфоцитов и их активационных маркеров в научной и клинической практике для изучения механизмов развития инфекционных, аллергических, аутоиммунных, посттрансплантационных процессов. Но в литературе встречается немного информации об экспрессии маркеров ранней и поздней активации на лимфоцитах НЧП, их референсных значениях и изменениях при моделировании патологических состояний на обезьянах. Поэтому методом проточной цитометрии были получены показатели основных и малых популяций лимфоцитов, а также активированных клеток периферической крови здоровых макак резус, определены интервалы распределения клеток и проведено сравнение с соответствующими показателями для человека. Клинические проявления моделируемых заболеваний у приматов и соответствующие лабораторные показатели могут зависеть не только от вида, но и от возраста животных, поэтому сравнение показателей неполовозрелых обезьян проводили с показателями условно здоровых детей и подростков, доступными из публикаций в отечественных научных изданиях.

Изменения показателей основных популяций лимфоцитов бывают недостаточно информативными, поэтому в работе определяли наличие и интервалы распределения малых популяций лимфоцитов $\left(\mathrm{CD}^{+}\right.$-НК-клеток, НКТ-клеток, двойных позитивных и двойных негативных Т-лимфоцитов) и активированных Т-лимфоцитов в периферической крови макак резус. 
У обезьян по сравнению с людьми выявлено большее содержание популяции $\mathrm{CD}^{+}$-НК-клеток, проявляющих повышенную литическую активность [20], что согласуется с данными литературы [21].

НКТ-клетки представляют собой гетерогенную популяцию Т-клеток, обеспечивающую связь между врожденным и адаптивным иммунитетом [22]. Выделяются отдельные разновидности НКТ-клеток, отличающиеся способностью вырабатывать цитокины $[23,24]$ и экспрессировать CD4 и CD8, а также быть двойными позитивными или двойными негативными по этим маркерам $[25,26]$. Эта подгруппа, по данным различных источников, составляет от < $1 \%$ [26] до 5-6 \% $[26,28]$ лимфоцитов периферической крови человека и НЧП. В результате проведенных работ выявлено, что НКТ-клетки - более малочисленная популяция у неполовозрелых макак резус по сравнению с детьми $[16,17]$.

Поскольку Т-лимфоциты представляют собой разнородную популяцию, то оценка их общего содержания является крайне неспецифичным тестом. Для понимания патогенеза инфекционных, аллергических и аутоиммунных заболеваний, посттрансплантационных реакций обычно исследуются отдельные популяции и субпопуляции Т-лимфоцитов, в той или иной степени однородные по своему фенотипу, степени зрелости и функциональному статусу [29]. Поэтому в работе изучали спонтанный уровень экспрессии на Т-клетках маркеров CD25 и HLA-DR как наиболее часто исследуемых при изучении активации лимфоцитов.

Экспрессия маркеров активации отражает функциональный статус лимфоцитов и может служить индикатором состояния всей иммунной системы в целом [30]. Различные активационные молекулы экспрессируются на поверхности лимфоцитов на стадиях их ранней и поздней активации, сопровождая развитие процессов пролиферации и апоптоза клеток. Экспрессия некоторых активационных молекул на поверхности лимфоцитов может усиливаться уже через несколько часов после индукции антигеном, в то же время повышение экспрессии может продолжаться в течение длительного времени [31].

Определение содержания $\mathrm{CD}^{+} \mathrm{CD} 25^{+}$-лимфоцитов широко используется в клинической практике для оценки ранней активации Т-лимфоцитов [32]. Однако популяция $\mathrm{CD} 3{ }^{+} \mathrm{CD} 25^{+}$-клеток весьма разнородна, поскольку CD25 может экспрессироваться на всех популяциях Т-лимфоцитов, в том числе и НКТ-клетках [30]. При сравнении данных об экспрессии CD25 на T-лимфоцитах общих, Т-хелперах, цитотоксических Т-лимфоцитах неполовозрелых макак резус и детей, выявлено, что у последних уровень экспрессии маркера на перечисленных популяциях выше на 40-80 \% [16]. Следует отметить, что границы нормы для общего количества $\mathrm{CD} 3^{+} \mathrm{CD} 25^{+}$-клеток у человека значительно варьируют: от 0,5-6,0 \% [26] до 11,5-13,4 \% [33]. Определена экспрессия CD25 на двойных позитивных и двойных негативных Т-лимфоцитах обезьян, она составила 4,5-
9,7 \% и 0,5-3,1 \% соответственно. Результаты, полученные при измерении экспрессии CD25 на Т-хелперах, цитотоксических и двойных позитивных Т-лимфоцитах макак резус, сопоставимы с данными из различных источников [27, 34, 35].

Популяция $\mathrm{CD}^{+} \mathrm{CD} 25^{+}$-Т-клеток гетерогенна по функциональным свойствам и фенотипическим признакам. Она включает пролиферирующие $\mathrm{CD} 4{ }^{+} \mathrm{CD} 25^{\text {low }}$ Т-клетки и $\mathrm{CD}^{+} \mathrm{CD} 25^{\text {high }}$-Трег [36]. Функцией Трег является поддержание клонального баланса лимфоидных клеток и предотвращение избыточной активации иммунной системы $[37,38]$. Трег дополнительно могут быть идентифицированы по наличию внутриядерного фактора транскрипции FOXP3 (FOXP3 ${ }^{+}$) и отсутствию поверхностного маркера CD127 (CD127-) [39]. Трег обследованных обезьян составили 4,7-6,1 \% от популяции хелперов, что сопоставимо с данными литературы $[27,34]$.

Молекула HLA-DR - поверхностный маркер лимфоцитов, принадлежащий к молекулам главного комплекса гистосовместимости МНС класса II, которые осуществляют презентацию антигена при развитии иммунного ответа на внеклеточные патогены [40]. HLA-DR является маркером не только поздней, но и длительной активации клеток, т. е. HLA-DR-позитивные лимфоциты продолжительно циркулируют в крови, а экспрессия этого маркера наиболее полно отражает активационное состояние клеток [30, 33]. Экспрессии HLA-DR на Т-лимфоцитах, Т-хелперах и цитотоксических T-лимфоцитах у макак резус была сопоставима с данными литературы [35]. Экспрессия HLA-DR на двойных позитивных и двойных негативных Т-лимфоцитах обезьян колебалась в широких пределах и составляла 3,3-8,5 \% и 8,1-16,9\% соответственно. Экспрессия маркера поздней активации HLA-DR на T-лимфоцитах макак резус оказалась в целом выше, чем маркера ранней активации CD25.

\section{Заключение}

Определение методом проточной цитометрии показателей основных, малых и активированных лимфоцитов макак резус позволит при моделировании заболеваний человека на животных оценить не только период начала иммунного ответа и его характер, но и даст возможность спрогнозировать течение заболевания, осуществить лабораторный мониторинг терапии, а в будущем позволит использовать лимфоциты в качестве мишеней терапевтического воздействия.

\section{Вклад авторов}

Концепция и дизайн исследования - Борисевич Г.В., Кутаев Д.А.; сбори обработкаматериала-БорисевичГ.В., Кириллов В.Б., Сизикова Т.Е.; статистическая обработка - Кириллова С.Л., Лебедев В.Н., Павельев Д.И.; Написание текста - Борисевич Г.В., Кириллова С.Л., Петров А.А.; редактирование - Борисевич С.В., Пантюхов В.Б., Пащенко Ю.И. 


\section{- Литература}

1. Хамитов Р.А., Салимов Р.М. Формирование европейских регуляторных правил использования обезьян при изучении лекарственных кандидатов. В кн.: Фундаментальные и прикладные аспекты медицинской приматологии : материалы III международной научной конференции. Сочи-Адлер, 8-10 августа 2016 г. Сочи : СТЕРХ ГРУПП, 2016: 51-60.

2. Кухаренко А.Е., Гравель И.В., Хамитов Р.А. Использование моделей in vivo для оценки иммуногенности терапевтических вакцин против ВПЧ на основе онкобелка Е7. Иммунология. 2015; 36 (1): $52-7$.

3 Лапин Б.А. К вопросу об использовании в медицинских экспериментах лабораторных приматов. Патологическая физиология и экспериментальная терапия. 2010; 2: 3-6.

4. Saalmüller A., Lunney J.K., Daubenberger C., Davis W., Fischer U., Göbel T.W. et al. Summary of the animal homologue section of HLDA8. Cell. Immunol. 2005; 236: 51-8. DOI: https://doi. org/10.1016/j.cellimm.2005.08.009

5. Хаитов Р.М. Иммунология: структура и функции иммунной системы : учебное пособие. 2-е изд., перераб. Москва : ГЭОТАРМедиа, 2019. 328 с

6. Хайдуков С.В., Зурочка А.В., Тотолян А.А., Черешнев В.А. Основные и малые популяции лимфоцитов периферической крови человека и их нормативные значения (методом многоцветного цитометрического анализа). Медицинская иммунология. 2009; 11 (2-3): 227-38. DOI: https://doi.org/10.15789/1563-0625-2009-2-3227-238

7. Xia H.J., Zhang G.H., Wang R.R., Zheng Y.T. The influence of age and sex on the cell counts of peripheral blood leukocyte subpopulations in Chinese rhesus macaques. Cell. Mol. Immunol. 2009; 6 (6): 433-40. DOI: https://doi.org/10.1038/cmi.2009.55

8. Хайдуков С.В., Байдун Л.В., Зурочка А.В., Тотолян А.А Стандартизованная технология «Исследование субпопуляционного состава лимфоцитов периферической крови с применением проточных цитофлюориметров-анализаторов». Российский иммунологический журнал. 2014; 4: 974-92. DOI: https://doi. org/10.15789/1563-0625-2012-3-255-268

9. Кудрявцев И.В., Субботовская А.И. Опыт измерения параметров иммунного статуса с использованием шестицветного цитофлуоримерического анализа. Медицинская иммунология. 2015; 17 (1): 19-26. DOI: https://doi.org/10.15789/1563-0625-2015-1$19-26$

10. Carter T.M., Shieh R.L., Blosser K.R., Chadwick J.B Margolick J.E.K., Hildreth J.E. et al. CD56 identifies monocytes and not natural killer cells in rhesus macaques. Cytometry. 1999; 37: 4150. DOI: https://doi.org/10.1002/(SICI)1097-0320(19990901)37:1

11. Webster R.L., Johnson R.P. Delineation of multiple subpopulations of natural killer cells in rhesus macaques Immunology. 2005; 115: 206-14. DOI: https://doi.org/10.1111 j.1365-2567.2005.02147.

12. Telford W.G., Babin S.A., Khorev S.V., Rowe S.H. Green fiber lasers: an alternative to traditional DPSS green lasers for flow cytometry. Cytometry A. 2009; 75 (12): 1031-9. DOI: https://doi. org/10.1002/cyto.a.20790.

13. Лакин Г.Ф. Биометрия : учебное пособие. 4-е изд., перераб. Москва : Высшая школа, 1990. 352 с.

14. Кубрава Д.Т., Медкова А.Ю., Синяшина Л.Н., Шевцова 3.В., Матуа А.3., Конджария И.Г. и др. Экспериментальный коклюш у обезьян. Вестник РАMH. 2013; 8: 28-33. DOI: https://doi. org/10.15690/vramn.v68i8.720

15. Лапин Б.А., Джикидзе Э.К., Фридман Э.П. Руководство по медицинской приматологии. Москва : Медицина, 1987. 192 с.

16. Пашнина И.А., Кшнясев И.А. Оценка особенностей субпопуляционного состава и экспрессии маркеров активации лимфоцитов периферической крови у детей с аутоиммунными заболеваниями соединительной ткани: дискриминантный анализ. Российский иммунологический журнал. 2015; 9 (2-2): 80-2.

17. Куропатенко М.В., Кудрявцев И.В., Азамова З.Ш., Платонова Н.Б., Нишева Е.С. Влияние паразитарных инвазий на результаты иммунофенотипирования клеток крови здоровых детей и детей с аллергическими заболеваниями. Российский иммунологический журнал. 2014; 8 (3): 818-22.

18. Лагерева Ю.Г., Беляева С.В., Бейкин Я.Б., Черешнев В.А. Гендер-специфические иммунологические различия у детей и взрослых. Российский иммунологический журнал. 2012; 6 (4): 363-9.
19. Крылова Р.И. Сравнительная характеристика нозологического профиля людей и обезьян разных видов. В кн.: Лабораторные приматы для решения актуальных проблем медицины и биологии : материалы конференции. Москва, 2004: 18-21.

20. Addison E.G., North J., Bakhsh I., Marden C., Haq S., AlSarraj S. et al. Ligation of CD8alpha on human natural killer cells prevents activation-induced apoptosis and enhances cytolytic activity. Immunology. 2005; 116 (3): 354-61. DOI: https://doi.org/10.1111/ j.1365-2567.2005.02235.x

21. Ibegbu C., Brodie-Hill A., Kourtis A.P., Carter A., McClure H., Wei Chen Z. Use of human CD3 monoclonal antibody for accurate $\mathrm{CD}^{+}$and $\mathrm{CD}^{+}$lymphocyte determinations in macaques: phenotypic characterization of the $\mathrm{CD}^{-} \mathrm{CD}^{+}$cell subset. J. Med. Primatol 2001; 30 (6): 291-8. DOI: https://doi.org/10.1034/j.1600-0684.2001. 300601

22. Кадагидзе 3.Г., Черткова А.И., Славина Е.Г. NКТ-клетки и противоопухолевый иммунитет. Российский биотерапевтический журнал. 2011; 10 (3): 9-15. DOI: https://doi.org/10.18027/22245057-2015-1-24-30

23. Bendelac A., Savage P.B., Teyton L. The biology of NKT cells. Annu. Rev. Immunol. 2007; 25: 297-336. DOI: https://doi org/10.1146/annurev.immunol.25.022106.141711

24. Drennan M.B., Govindarajan S., De Wilde K., Schlenner S.M., Ware C., Nedospasov S. et al. The thymic microenvironment differentially regulates development and trafficking of invariant NKT cell sublineages. J. Immunol. 2014; 193 (12): 5961-72. DOI: https:// doi.org/10.4049/jimmunol.1401601

25. Mittag A., Lenz D., Gerstner A.O.H., Sack U., Steinbrecher M., Koksch M. et al. Polychromatic (eight-color) slide-based cytometry for the phenotyping of leukocyte, NK, and NKT subsets. Cytometry A. 2005; 65A: 103-115. DOI: https://doi.org/10.1002/cyto.a. 20140

25. Зурочка А.В., Хайдуков С.В., Кудрявцев И.В., Черешнев В.А. Проточная цитометрия в медицине и биологии. Екатеринбург : УpO PAH, 2014. 576 c.

27. Rout N., Kaur A. Cellular immune responses in natural and non-natural hosts of simian immunodeficiency virus infection. In: Natural Hosts of SIV. 2014: 197-215.

28. Araki M., Kondo T., Gumperz J.E., Brenner M.B., Miyake S, Yamamura T. Th2 bias of $\mathrm{CD}^{+}$NKT cells derived from multiple sclerosis in remission. Int. Immunol. 2003; 15: 279-88. DOI: https:// doi.org/10.1093/intimm/dxg029

29. Черешнев В.А., Шмагель К.В. Иммунология. Москва МАГИСТР-ПРЕСС, 2013. 448 с.

30. Литвинова Л.С., ГуцолА.А., СохоневичН.А., КофановаК.А., Хазиахматова О.Г., Шуплецова В.В. и др. Основные поверхностные маркеры функциональной активности Т-лимфоцитов Медицинская иммунология. 2014; 16 (1): 7-26. DOI: https://doi. org/10.15789/1563-0625-2014-1-7-26

31. Wieland E., Shipkova M. Lymphocyte surface molecules as immune activation biomarkers. Clin. Biochem. 2016; 49 (4-5): 347 54. DOI: https://doi.org/10.1016/j.clinbiochem.2015.07.099

32. Хаитов Р.М., Пинегин Б.В., Ярилин А.А. Руководство по клинической иммунологии. Диагностика заболеваний иммунной системы : руководство для врачей. Москва : ГЭОТАР-Медиа, 2009: $352 \mathrm{c}$.

33. Rea I.M., Mcnerlan S.E., Alexander H.D. CD69, CD25, and HLA-DR activation antigen expression on CD31 lymphocytes and relationship to serum TNF- $\alpha$, IFN- $\gamma$, and Sil-2r levels in aging. Exp. Gerontol. 1999; 34 (1): 79-93. DOI: https://doi.org/10.1016/s05315565(98)00058-8

34. Magalhaes I., Vudattu N.K., Ahmed R.K., KuhlmannBerenzon S., Ngo Y., Sizemore D.R. High content cellular immune profiling reveals differences between rhesus monkeys and men. Immunology. 2010; 131: 128-40. DOI: https://doi.org/10.1111/j.13652567.2010.03284.x

35. Sopper S., Stahl-Hennig C., Demuth M., Johnston I.C.D. Dorries R., ter Meulen V. Lymphocyte subsets and expression of differentiation markers in blood and lymphoid organs of rhesus monkeys. Cytometry. 1997; 29: 351-62. DOI: https://doi.org/10.1002/ (sici)1097-0320(19971201)29:4

36. Хайдуков С.В., Зурочка А.В. Цитометрический анализ субпопуляций Т-хелперов (Th1, Th2, Treg, Th17, активированные Т-хелперы). Медицинская иммунология. 2011; 13 (1): 7-16. DOI: https://doi.org/10.15789/1563-0625-2011-1-7-16 
37. Sakaguchi S. Regulatory T cells: history and perspective. Methods Mol. Biol. 2011; 707:3-17. DOI: https://doi.org/10.1007/978$1-61737-979-61$

38. Гариб Ф.Ю., Ризопулу А.П. Стратегия иммунной эвазии патогенов: супрессия иммунного ответа путем активирования Т-регуляторных клеток хозяина. Иммунология. 2016; 37 (1): 35 46. DOI: https://doi.org/10.18821/0206-4952-2016-37-1-35-46
39. Fazekas de StGroth B., Zhu E., Asad S., Lee L. Flow cytometric detection of human regulatory T cells. Methods Mol. Biol. 2011; 707: 273-9. DOI: https://doi.org/10.1007/978-1-61737-9796_17

40. Ярилин А.А. Иммунология : учебник. Москва : ГЭОТАРМедиа; 2010. 752 с.

\section{- References}

1. Khamitov R.A., Salimov R.M. Formation of European regulatory rules for the use of monkeys in studies of drug candidates. In: Fundamental and Applied Aspects of Medical Primatology. Proceedings of the international scientific conference. Sochi-Adler, August 8-10, 2016. Sochi: STERH GRUPP, 2016: 51-60. (in Russian)

2. Kukharenko A.E., Gravel' I.V., Khamitov R.A. Use of in vivo models to assess the immunogenicity of therapeutic HPV vaccines based on the E7 oncoprotein. Immunologiya. 2015; 36 (1): 52-7. (in Russian)

3. Lapin B.A. To the question of use of laboratory primates in medical experiments. Patologicheskaya fiziologiya i eksperimental'naya terapiya. 2010; 2: 3-6. (in Russian)

4. Saalmüller A., Lunney J.K., Daubenberger C., Davis W., Fischer U., Göbel T.W., et al. Summary of the animal homologue section of HLDA8. Cell. Immunol. 2005; 236: 51-8. DOI: https://doi. org/10.1016/j.cellimm.2005.08.009

5. Khaitov R.M. Immunology: structure and function of immune system. Textbook. 2nd ed., revised. Moscow: GEOTAR-Media, 2019: 328 p. (in Russian)

6. Khaydukov S.V., Zurochka A.V., TotolianA.A., Chereshnev V.A. Major and lymphocyte populations of human peripheral blood lymphocytes and their reference values, as assayed by multi-colour cytometry. Meditsinskaya immunologiya, 2009; 11 (2-3): 227-38. DOI: https://doi.org/10.15789/1563-0625-2009-2-3-227-238 (in Russian)

7. Xia H.J., Zhang G.H., Wang R.R., Zheng Y.T. The influence of age and sex on the cell counts of peripheral blood leukocyte subpopulations in Chinese rhesus macaques. Cell. Mol. Immunol. 2009; 6 (6): 433-40. DOI: https://doi.org/10.1038/cmi.2009.55

8. Khaydukov S.V., Baydun L.V., Zurochka A.V., Totolyan A.A. The standardised technique: «Study subpopulations of peripheral blood lymphocytes by using flow cytometry». Rossiyskiy immunologicheskiy zhurnal. 2014; 4: 974-92. DOI: https://doi.org/10.15789/15630625-2012-3-255-268 (in Russian)

9. Kudryavtsev I.V., Subbotovskaya A.I. Application of six-color flow cytometric analysis for immune profile monitoring. Meditsinskaya immunologiya, 2015; 17 (1): 19-26. DOI: https://doi. org/10.15789/1563-0625-2015-1-19-26 (in Russian)

10. Carter T.M., Shieh R.L., Blosser K.R., Chadwick J.B., Margolick J.E.K., Hildreth J.E., et al. CD56 identifies monocytes and not natural killer cells in rhesus macaques. Cytometry. 1999; 37: 41-50. DOI: https://doi.org/10.1002/(SICI)1097-0320(19990901)37:1

11. Webster R.L., Johnson R.P. Delineation of multiple subpopulations of natural killer cells in rhesus macaques. Immunology. 2005; 115: 206-14. DOI: https://doi.org/10.1111/j.1365-2567.2005.02147.

12. Telford W.G., Babin S.A., Khorev S.V., Rowe S.H. Green fiber lasers: an alternative to traditional DPSS green lasers for flow cytometry. Cytometry A. 2009; 75 (12): 1031-9. DOI: https://doi. org/10.1002/cyto.a.20790.

13. Lakin G.F. Biometrics: Textbook. $4^{\text {th }}$ ed., revised. Moscow: Vysshaya shkola, 1990: 352 p. (in Russian)

14.KubravaD.T., MedkovaA.Yu., SinyashinaL.N., ShevtsovaZ.A., Matua A.Z., Kondzariya I.G., et al. Experimental whooping cough of nonhuman primate . Vestnik RAMN. 2013; 8: 28-33. DOI: https://doi. org/10.15690/vramn.v68i8.720 (in Russian)

15. Lapin B.A., Dzhikidze E.K., Fridman E.P. Guide to medical primatology. Moscow: Meditsina, 1987: 192 p. (in Russian)

16. Pashnina I.A., Kshnyasev I.A. The assessment of estimate of subpopulation structure and activaion molecules expression on peripheral blood lymphocytes in children with autoimmune diseases of connective tissue: discriminant analyses. Rossiyskiy immunologicheskiy zhurnal. 2015; 9 (2-2): 80-2. (in Russian)

17. Kuropatenko M.V., Kudravtsev I.V., Azamova Z.Sh., Platonova N.B., Nisheva E.S. Parasitic invasion influence on immune cells phenotyping results for healthy and allergic children. Rossiyskiy immunologicheskiy zhurnal. 2014; 8 (3): 818-22. (in Russian)
18. Lagereva Yu.G., Belyaeva S.V., Beykin Ya.B., Chereshnev V.A. Gender specific immune status differences in children and adults. Rossiyskiy immunologicheskiy zhurnal. 2012; 6 (4): 363-9. (in Russian)

19. Krylova R.I. Comparative characteristics of the nosological profile of people and monkeys of different species. In: Laboratory Primates for Solving Urgent Problems of Medicine and Biology. Proceedings of the conference. Moscow, 2004: 18-21. (in Russian)

20. Addison E.G., North J., Bakhsh I., Marden C., Haq S., AlSarraj S., et al. Ligation of CD8alpha on human natural killer cells prevents activation-induced apoptosis and enhances cytolytic activity. Immunology. 2005; 116 (3): 354-61. DOI: https://doi.org/10.1111/ j.1365-2567.2005.02235.x

21. Ibegbu C., Brodie-Hill A., Kourtis A.P., Carter A., McClure H., Wei Chen Z. Use of human CD3 monoclonal antibody for accurate $\mathrm{CD}^{+}$and $\mathrm{CD}^{+}$lymphocyte determinations in macaques: phenotypic characterization of the $\mathrm{CD}^{-} \mathrm{CD}^{+}$cell subset. J. Med. Primatol. 2001; 30 (6): 291-8. DOI: https://doi.org/10.1034/j.1600-0684.2001. 300601

22. Kadagidze Z.G., Chertkova A.I., Slavina E.G. NKT-cells and antitumor immunity Rossiyskiy bioterapevticheskiy zhurnal. 2011; 10 (3): 9-15. DOI: https://doi.org/10.18027/2224-5057-2015-1-24-30 (in Russian)

23. Bendelac A., Savage P.B., Teyton L. The biology of NKT cells. Annu. Rev. Immunol. 2007; 25: 297-336. DOI: https://doi. org/10.1146/annurev.immunol.25.022106.141711

24. Drennan M.B., Govindarajan S., De Wilde K., Schlenner S.M., Ware C., Nedospasov S., et al. The thymic microenvironment differentially regulates development and trafficking of invariant NKT cell sublineages. J. Immunol. 2014; 193 (12): 5961-72. DOI: https://doi. org/10.4049/jimmunol.1401601

25. Mittag A., Lenz D., Gerstner A.O.H., Sack U., Steinbrecher M., Koksch M., et al. Polychromatic (eight-color) slide-based cytometry for the phenotyping of leukocyte, NK, and NKT subsets. Cytometry A. 2005; 65A: 103-115. DOI: https://doi.org/10.1002/cyto.a.20140

26. ZurochkaA.V., Khaydukov S.V., Kudryavtsev I.V., Chereshnev V.A. Flow cytometry in medicine and biology. Ekaterinburg: UrO RAN, 2014: 576 p. (in Russian)

27. Rout N., Kaur A. Cellular immune responses in natural and non-natural hosts of simian immunodeficiency virus infection. In: Natural Hosts of SIV. 2014: 197-215.

28. Araki M., Kondo T., Gumperz J.E., Brenner M.B., Miyake S., Yamamura T. Th2 bias of CD4 $4^{+}$NKT cells derived from multiple sclerosis in remission. Int. Immunol. 2003; 15: 279-88. DOI: https://doi. org/10.1093/intimm/dxg029

29. Chereshnev V.A, Schmagel' K.V. Immunology. Moscow: MAGISTR-PRESS; 2013: 448 p. (in Russian)

30. Litvinova L.S., GutsolA.A., Sokhonevich N.A., Kofanova K.A. Khaziakhmatova O.G., Shupletsova V.V., et al. Basic surface markers of functional activity T-lymphocytes. Meditsinskaya immunologiya. 2014; 16 (1): 7-26. DOI: https://doi.org/10.15789/1563-0625-2014-17-26 (in Russian)

31. Wieland E., Shipkova M. Lymphocyte surface molecules as immune activation biomarkers. Clin. Biochem. 2016; 49 (4-5): $347-$ 54. DOI: https://doi.org/10.1016/j.clinbiochem.2015.07.099

32. Khaitov R. M., Pinegin B.V., Yarilin A.A. Guidelines for clinical immunology. diagnosing immune system diseases: A guide for physicians Moscow: GEOTAR-Media, 2009: 352 p. (in Russian)

33. Rea I.M., Mcnerlan S.E., Alexander H.D. CD69, CD25, and HLA-DR activation antigen expression on CD31 lymphocytes and relationship to serum TNF- $\alpha$, IFN- $\gamma$, and Sil-2r levels in aging. Exp. Gerontol. 1999; 34 (1): 79-93. DOI: https://doi.org/10.1016/s05315565(98)00058-8

34. Magalhaes I., Vudattu N.K., Ahmed R.K., KuhlmannBerenzon S., Ngo Y., Sizemore D.R. High content cellular immune profiling reveals differences between rhesus monkeys and men. Im- 
munology. 2010; 131: 128-40. DOI: https://doi.org/10.1111/j.13652567.2010.03284.x

35. Sopper S., Stahl-Hennig C., Demuth M., Johnston I.C.D., Dorries R., ter Meulen V. Lymphocyte subsets and expression of differentiation markers in blood and lymphoid organs of rhesus monkeys. Cytometry. 1997; 29: 351-62. DOI: https://doi.org/10.1002/ (sici) 1097-0320(19971201)29:4

36. Khaydukov S.V., Zurochka A.V. Analysis of t helper subpopulations (Th1, Th2, Treg, Th17, activated T-helpers) by means of flow cytometry. Meditsinskaya immunologiya, 2011; 13 (1): 7-16. DOI: https://doi.org/10.15789/1563-0625-2011-1-7-16 (in Russian)

\section{Сведения об авторах}

Борисевич Галина Валентиновна - к.б.н., старший научный сотрудник отдела ФГБУ «48 ЦНИИ» Минобороны России, Сергиев Посад-6, Российская Федерация; e-mail: 48cnii@mil.ru, http:// orcid.org/0000-0002-0843-9427

Кириллова Светлана Леонидовна - д.б.н., ведущий научный сотрудник отдела ФГБУ «48 ЦНИИ» Минобороны России, Сергиев Посад-6, Российская Федерация; e-mail: 48cnii@mil.ru, http://orcid.org/0000-0003-1245-9225

Петров Александр Анатольевич - д.м.н., начальник отдела ФГБУ «48 ЦНИИ» Минобороны России, Сергиев Посад-6, Российская Федерация; e-mail: 48cnii@mil.ru, http://orcid.org/00000002-9714-2085

Лебедев Виталий Николаевич - д.б.н., проф., ведущий научный сотрудник отдела ФГБУ «48 ЦНИИ» Минобороны России, Сергиев Посад-6, Российская Федерация; e-mail: 48cnii@mil.ru, http://orcid.org/0000-0002-6552-4599

Пащенко Юрий Иванович - д.б.н., проф., ведущий научный сотрудник отдела ФГБУ «48 ЦНИИ» Минобороны России, Сергиев Посад-6, Российская Федерация; e-mail: 48cnii@mil.ru, http:// orcid.org/0000-0002-4094-3885

Кириллов Владимир Борисович - д.б.н., старший научный сотрудник отдела ФГБУ «48 ЦНИИ» Минобороны России, Сергиев Посад-6, Российская Федерация; e-mail: 48cnii@mil.ru, http:// orcid.org/0000-0003-2916-0668

Сизикова Татьяна Евгеньевна - к.б.н., научный сотрудник отдела ФГБУ «48 ЦНИИ» Минобороны России, Сергиев Посад-6, Российская Федерация; e-mail: 48cnii@mil.ru, http://orcid. org/0000-0002-1817-0126

Павельев Дмитрий Игоревич - научный сотрудник отдела ФГБУ «48 ЦНИИ» Минобороны России, Сергиев Посад-6, Российская Федерация; e-mail: 48cnii@mil.ru, http://orcid.org/00000003-3204-1897

Пантюхов Владимир Борисович - к.м.н., начальник управления ФГБУ «48 ЦНИИ» Минобороны России, Сергиев Посад-6, Российская Федерация; e-mail: 48cnii@mil.ru, http://orcid org/0000-0002-1313-2059

Кутаев Дмитрий Анатольевич - к.б.н., зам. начальника по научной работе ФГБУ «48 ЦНИИ» Минобороны России, Сергиев Посад-6, Российская Федерация; е-mail: 48cnii@mil.ru

Борисевич Сергей Владимирович - член-корр. РАН, д.б.н., проф., начальник ФГБУ «48 ЦНИИ» Минобороны России, Сергиев Посад-6, Российская Федерация; e-mail: 48cnii@mil.ru, http:/ orcid.org/0000-0002-6742-3919
37. Sakaguchi S. Regulatory T cells: history and perspective. Methods Mol. Biol. 2011; 707: 3-17. DOI: https://doi.org/10.1007/978-161737-979-6

38. Garib F.Yu., Rizopulu A.P. Strategy of immune evasion of pathogens: the suppression of immune response by host's t-regulatory cells activation. Immunologiya. 2016; 37 (1): 35-46. DOI: https://doi. org/10.18821/0206-4952-2016-37-1-35-46. (in Russian)

39. Fazekas de StGroth B., Zhu E., Asad S., Lee L. Flow cytometric detection of human regulatory T cells. Methods Mol. Biol. 2011; 707: 273-9. DOI: https://doi.org/10.1007/978-1-61737-979-6 17

40. Yarilin A.A. Immunology: A textbook. Moscow: GĒOTARMedia, 2010: 752 p. (in Russian)

\section{Authors' information}

Galina V. Borisevich - PhD, Senior Researcher of Department of 48 CSRI of the Ministry of Defense of the Russian Federation, Sergiev Posad-6, Russian Federation; e-mail: 48cnii@mil.ru, http://orcid. org/0000-0002-0843-9427

Svetlana L. Kirillova - Dr.Sci. (Biol.), Leader Researcher of Department of 48 CSRI of the Ministry of Defense of the Russian Federation, Sergiev Posad-6, Russian Federation; e-mail: 48cnii@mil.ru, http://orcid.org/0000-0003-1245-9225

Alexander A. Petrov - MD, Head of Department of 48 CSRI of the Ministry of Defense of the Russian Federation, Sergiev Posad-6, Russian Federation; e-mail: 48cnii@mil.ru, http://orcid.org/00000002-9714-2085

Vitaliy N. Lebedev - Dr.Sci.(Biol.), Prof., Leader Researcher of Department of 48 CSRI of the Ministry of Defense of the Russian Federation, Sergiev Posad 6, Russian Federation; e-mail: 48cnii@mil.ru, http://orcid.org/0000-0002-6552-4599

Yuri I. Pashchenko - Dr.Sci.(Biol.), Prof., Leader Researcher of Department of «48 CSRI» of the Ministry of Defense of the Russian Federation,SergievPosad-6,RussianFederation;e-mail:48cnii@mil.ru, http://orcid.org/0000-0002-4094-3885

Vladimir B. Kirillov - Dr.Sci. (Biol.), Senior Researcher of Department of 48 CSRI of the Ministry of Defense of the Russian Federation, Sergiev Posad-6, Russian Federation; e-mail: 48cnii@mil.ru, http://orcid.org/0000-0003-2916-0668

Tatyana E. Sizikova - PhD, Researcher of Department of 48 CSRI of the Ministry of Defense of the Russian Federation, Sergiev Posad-6, Russian Federation; e-mail: 48cnii@mil.ru, http://orcid org/0000-0002-1817-0126

Dmitriy I. Pavel'ev - Researcher of Department of 48 CSRI of the Ministry of Defense of the Russian Federation, Sergiev Posad-6, Russian Federation; e-mail: 48cnii@mil.ru, http://orcid.org/00000003-3204-1897

Vladimir B. Pantyukhov - PhD, Head of Department of 48 CSRI of the Ministry of Defense of the Russian Federation, Sergiev Posad-6, Russian Federation; e-mail: 48cnii@mil.ru, http://orcid.org/00000002-1313-2059

Dmitriy A. Kutaev - PhD, Deputy Head for scientific work, 48 CSRI of the Ministry of Defense of the Russian Federation, Sergiev Posad-6, Russian Federation; e-mail: 48cnii@mil.ru

Sergey V. Borisevich - Corresponding Member of RAS, Dr.Sci (Biol.), Prof., Head of 48 CSRI of the Ministry of Defense of the Russian Federation, Sergiev Posad-6, Russian Federation; e-mail: 48cnii@mil.ru, http://orcid.org/0000-0002-6742-3919 